\title{
Siderophore (from Synechococcus sp. PCC 7002)-Chelated Iron Promotes Iron Uptake in Caco-2 Cells and Ameliorates Iron Deficiency in Rats
}

\author{
Xue Feng, Suisui Jiang, Fan Zhang, Runfang Wang, Yuanhui Zhao* ${ }^{\mathbb{C}}$ and Mingyong Zeng * \\ College of Food Science and Engineering, Ocean University of China, Qingdao, Shandong 266003, China; \\ 21170731078@stu.ouc.edu.cn (X.F.); 11170711017@stu.ouc.edu.cn (S.J.); 21170711076@stu.ouc.edu.cn (F.Z.); \\ 21170731082@stu.ouc.edu.cn (R.W.) \\ * Correspondence: zhaoyuanhui@ouc.edu.cn (Y.Z.); mingyz@ouc.edu.cn (M.Z.); \\ Tel./Fax: +86-53-28-2032-400 (Y.Z.); +86-53-28-2032-783 (M.Z.)
}

Received: 20 November 2019; Accepted: 11 December 2019; Published: 16 December 2019

\begin{abstract}
Siderophores are iron chelators with low molecular weight secreted by microorganisms. Siderophores have the potential to become natural iron fortifiers. To explore the feasibility of the application of Synechococcus sp. PCC7002-derived siderophores as iron fortifiers, Synechococcus sp. PCC7002, as a carrier, was fermented to produce siderophores. The absorption mechanism and anemia intervention effect of siderophores-chelated iron (SCI) were studied through the polarized Caco-2 Cell monolayers and the rat model of iron-deficiency anemia, respectively. The results indicated that siderophores (from Synechococcus sp. PCC7002) had an enhancing effect on iron absorption in polarized Caco-2 cell monolayers. The main absorption site of SCI was duodenum with $\mathrm{pH} 5.5$, and the absorption methods included endocytosis and DMT1, with endocytosis being dominant. The effect of sodium phytate on SCI was less than that of ferrous sulfate. Therefore, SCI could resist inhibitory iron absorption factors in polarized Caco-2 cell monolayers. SCI showed significantly higher relative bioavailability $(133.58 \pm 15.42 \%)$ than ferrous sulfate $(100 \pm 14.84 \%)$ and ferric citrate $(66.34 \pm 8.715 \%)$ in the rat model. Food intake, hemoglobin concentration, and hematocrit and serum iron concentration of rats improved significantly after Fe-repletion. Overall, this study indicated that siderophores derived from Synechococcus sp. PCC7002 could be an effective and feasible iron nutritive fortifier.
\end{abstract}

Keywords: Synechococcus sp. PCC 7002; siderophores; Caco-2 cell; iron-deficiency anemia; anemia intervention

\section{Introduction}

Iron plays an important role in maintaining normal human metabolism and is essential for most organisms [1]. However, iron deficiency is a ubiquitous micronutrient deficiency worldwide. Iron-deficiency anemia (IDA) caused by iron deficiency could lead to multiple pathologies, especially delays in development and behavior among children [2-4]. Over two billion people worldwide suffer from this problem, according to the FAO (Food and Agriculture Organization) [2,5].

Iron deficiency and IDA arise when requirements cannot be met by dietary iron, particularly in developing countries, primarily due to insufficient iron content in food and low iron absorption efficiency. This is because iron digestion and absorption are often inhibited by the various dietary components, such as oxalates and phytate. Therefore, food fortification and supplementation-with ferrous sulfate and ferric sodium EDTA, for example-are commonly used to combat IDA [6]. However, ferrous sulfate could affect appetite and digestion due to its side effects on the stomach, and ferric sodium EDTA is a synthetic chelating agent, the safety of which is a concern for the public, resulting in 
lower daily intakes [7]. Therefore, improving the intake and bioavailability of dietary iron is considered to be an effective way to combat IDA $[8,9]$.

Siderophores are low-molecular-weight compounds secreted by microbes, several fungi, and plants under limited iron condition [10]. They could facilitate acquisition of iron and counter the iron deficiency by high-affinity iron (III) ligands [10]. Compared with other metal elements, iron is preferentially chelated by siderophores [11]. Moreover, only ferric iron could be chelated by siderophores. When ferric iron is reduced to ferrous iron, it will be released by siderophores. It is an important strategy for microbes to combat the iron stress environment $[10,12]$. The role of siderophores in microbial physiological activities is to dissolve ferric iron and transport it into the cytoplasm, so siderophores have the potential to become a nutritional fortifier [13]. The hypothesis was partly verified in the plant nutrition field.

Siderophores have two major structural features, $\alpha$-Hydroxy-carboxylate acid ( $\alpha$-hydroxy aspartic acid and citric acid) and amphipathy in the form of polar head and hydrophobic tail. The majority of marine siderophores have both distinctive structural features [10]. Accordingly, they both contain amphipathy and photochemistry in Fe(III) complexes. Siderophores could anchor a certain gradient outside the cell membrane, depending on membrane affinity and length, thereby enhancing the ability to capture iron from seawater $[12,14]$.

Synechococcus sp. PCC7002 is an elucidated unicellular marine cyanobacterium and could produce siderophores of multiple types. After optimizing the culture conditions, Synechococcus sp. PCC7002 can grow at a multiple rate within three hours. It could also produce more ferritin under iron-limited conditions. In particular, siderophores with the structure of $\alpha$-Hydroxy-carboxylate, which were separated by Martinez, have different fatty acid chains and hang outside the cell membrane to capture ferric iron [15]. Therefore, the microalgae are a suitable carrier strain for producing siderophores. Our previous study identified the culture conditions of Synechococcus sp. PCC7002; therefore, it has the foundation to become an iron nutrition enhancer.

This paper aimed to study the intestinal absorption effect of SCI by the polarized Caco-2 Cell monolayers and verify the anemia intervention effect of SCI through the iron-deficiency anemia rat model. By analyzing the iron intestinal absorption effect and bioavailability of SCI, the feasibility of $\mathrm{SCI}$ to become an iron nutrition enhancer was explored.

\section{Results}

\subsection{Analysis of Siderophore Absorption Site in Polarized Human Intestinal Epithelial (Caco-2) Cells}

As shown in Figure 1a, the fluorescence intensity exhibited a sharp decrease over culture time, which indicated that a high SFE-Fe absorption appeared in polarized Caco- 2 cell monolayers. The absorption at $\mathrm{pH} 5.5$ was higher than that at $\mathrm{pH} 7.0$, which showed that acidic the environment was more suitable for SFE-Fe absorption than the neutral one. This result could be explained by the fact that exogenous iron entered the acidic duodenum first, followed by the jejunum and then the other parts of the intestine during iron digestion and absorption [16,17]. Therefore, consistent with other forms of iron, SFE-Fe was mainly absorbed in the duodenum. Because intestinal iron absorption primarily occurred in the duodenum close to the stomach (when fasting, $\mathrm{pH}=6.1$; when eating, $\mathrm{pH}=5.5$ ) [18]. For clear results, only the result of $\mathrm{pH} 5.5$ was shown in the following experiments. 
(a)

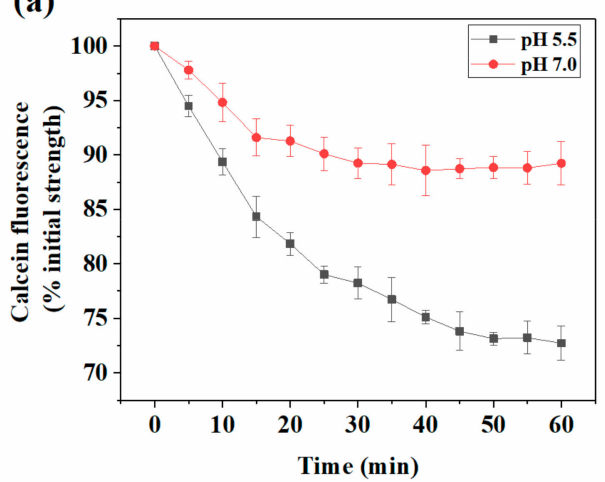

(b)



Figure 1. (a) Iron intake content of SFE-Fe in polarized Caco-2 cell monolayers with different $\mathrm{pH}$. (b) Iron uptake content of SFE-Fe, SCE-Fe, and SFP-Fe in polarized Caco-2 cell monolayers. Values are expressed as means \pm standard deviations $(n=3)$.

\subsection{The Effect of Different Extraction Methods on Iron Absorption}

As shown in Figure 1b, when SFE-Fe, SCE-Fe, and SFP-Fe (from different extraction methods) were added, respectively, the trend of fluorescence intensity was consistent. Therefore, different extraction methods and purity had no difference in regard to iron absorption. The following experiments showed only the result of SFE-Fe.

\subsection{Analysis of Siderophore Absorption Methods in Polarized Caco-2 Cell Monolayers}

Most of the iron was absorbed through DMT1 (Ferrous iron) or endocytosis (ferric oxyhydroxide nanoparticles) $[8,19,20]$. BPDS is a powerful complexing agent of ferrous ion. Excessive BPDS could block the absorption and transport pathway of divalent iron mediated by DMT1 through complexing all ferrous ions in solution. Ferrous sulfate, a ferrous salt, was absorbed only through the DMT1 pathway. Therefore, as shown in Figure 2a, it was fully blocked by BPDS. However, SFE-Fe was almost unaffected by BPDS. Compared to SFE-Fe only, the absorption of SFE-Fe with BPDS had no significant difference. Compared to SFE-Fe only, the fluorescence intensity of SFE-Fe with BPDS significantly decreased, but by less than $5 \%$. The results suggested that SFE-Fe was absorbed primarily by endocytosis directly, and a small portion of the iron was absorbed through the DMT1 pathway.

(a)



(b)

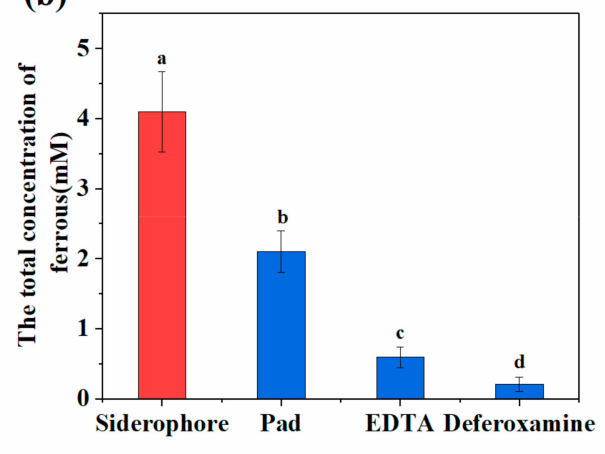

Figure 2. (a) Iron intake content of SFE-Fe in polarized Caco-2 cell monolayers when BPDS adding. (b) The ferrous concentrations of different sample when incubated for $2 \mathrm{~h}$ in polarized Caco-2 cell monolayers (Pad: sodium phytate). Values are expressed as means \pm standard deviations $(\mathrm{n}=3)$. Bars with different letters are significantly different $(p<0.05)$. 


\subsection{Analysis of Reduction and Absorption of SFE-Fe in Polarized Caco-2 Cell Monolayers}

The reduced iron content of SFE-Fe by Dcytb could be measured according to the determination of ferrous iron, which combined with BPDS and could be analyzed through colorimetry thereafter [21]. The reduced iron content observed during the iron-absorption experiment was measured (Figure 2b) when iron was chelated by SFE, sodium phytate, EDTA, and DFB, respectively. SFE-Fe was more easily reduced than EDTA (common chelating agent), DFB (a kind of siderophores), and sodium phytate $(p<0.01)$. The result indicated that the reduction of SFE-Fe was inclined to Dcypt, rather than to others. SFE-Fe was easily reduced to ferrous iron natively and subsequently absorbed due to the unique existing structure of citric acid and hydroxamic acid. The fact that the absorption of SFE-Fe was blocked by BPDS also partly supported this possibility (Figure 2a).

\subsection{Effect of Sodium Phytate on the Absorption of Siderophores-Chelated Iron Intestinal Cells}

Iron was easily combined with some plant food ingredients induced to the formation of precipitate, which could hinder iron absorption in intestinal cells [22]. Some iron fortifiers, especially ferrous salt, showed a good effect on iron absorption in vitro $[23,24]$. However, these fortifiers were subject to precipitation by organic acids in the intestines, and the bioavailability was sharply decreased [25]. As shown in Figure 3a, a significant difference was found between SFE-Fe and ferrous sulfate with the addition of equal concentrations of sodium phytate. Sodium phytate had six ligands. It could chelate with ferrous iron or higher metal ions to form precipitation rapidly under acidic conditions. Therefore, when sodium phytate was added, the absorption of ferrous sulfate was seriously inhibited. A significant reduction of SFE-Fe absorption was found with sodium phytate added. Therefore, sodium phytate did not have a significant inhibition effect on SFE-Fe compared to ferrous sulfate.

(a)



(b)

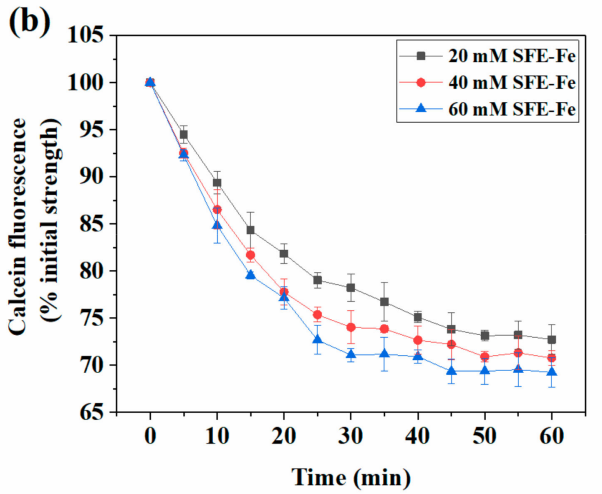

Figure 3. (a) The effect of sodium phytate on iron uptake of SFE-Fe in polarized Caco-2 cell monolayers (Pad: sodium phytate;). (b) Iron uptake content of SFE-Fe with different concentrations in polarized Caco-2 cell monolayers. Values are expressed as means \pm standard deviations $(n=3)$.

\subsection{Effect of SFE-Fe on the Metabolic Balance in Intestinal Cells}

To investigate the effect of SFE-Fe on metabolic balance for intestinal cells, three different concentration $(20,40$, and $60 \mu \mathrm{M})$ of SFE-Fe were added in Caco-2 cells, and the fluorescence intensity change of calcein is shown in Figure 3b. A sharp increase of LIP iron appeared in the first $25 \mathrm{~min}$, and then the increase rate was greatly reduced until the calcein fluorescence value stabilized. Moreover, no significant difference in the final stable fluorescence intensity was found during these time periods. The result indicated that the absorption of SFE-Fe was adjusted by intestinal iron metabolism balance mechanism, which could not be destroyed by the intake of SFE-Fe.

\subsection{Measurement of Diet Intake on the Growth and Development of Rats}

Iron deficiency could cause low hemoglobin concentration and deficiency of iron enzyme, which initiates systemic dysfunction and abnormal macrophage secretion, further damaging immune 
function $[8,26,27]$. The rat body weight and diet intake of different groups are shown in Table 1 . The diet intake of ferrous sulfate was significantly lower than SFE-Fe. It might because that inorganic salt, ferrous sulfate had side effects on the stomach and affected appetite and digestion [9]. The weight gain of SFE-Fe was significantly higher than ferrous sulfate and ferric citrate groups, which suggested that SFE-Fe had considerable advantages in promoting appetite and growth in rats. There was no significant difference between ferrous sulfate and ferric citrate regarding weight after the Fe-repletion period. Apparently, due to the side effect on the intestines, ferrous sulfate influenced the body weight gain of rats and showed no difference with ferrous citrate (trivalent iron), which was also harmless to the intestines.

Table 1. The weight changes and diet intakes of rates at the end of iron repletion period. Values are expressed as means \pm standard deviations $(n=8)$. Different lowercase letters in the same column indicate significant differences between groups and intragroup, respectively; $(p<0.05)$.

\begin{tabular}{cccccc}
\hline \multirow{2}{*}{ Group } & Iron Repletion & & \\
\cline { 2 - 6 } & Control & Fe-Deficient & FeSO $_{4}$ & SFC-Fe & Ferric Citrate \\
\hline $\mathrm{N}$ & 8 & 8 & 8 & 8 & 8 \\
Diet iron (mg/Kg) & $36.7 \pm 0.12$ & $13.08 \pm 1.34$ & $29.11 \pm 0.9$ & $29.56 \pm 1.3$ & $33.32 \pm 0.92$ \\
Diet intake (g) & 348.64 & 247.36 & 286.77 & 316.01 & 259.78 \\
Initial BW (g) & $254.5 \pm 25.66^{\mathrm{a}}$ & $170.13 \pm 28.74^{\mathrm{b}}$ & $170.33 \pm 31.76^{\mathrm{b}}$ & $171.25 \pm 18.99 \mathrm{~b}$ & $170.13 \pm 19.08^{\mathrm{b}}$ \\
Final BW (g) & $356.5 \pm 32.93^{\mathrm{a}}$ & $205.38 \pm 31.15^{\mathrm{b}}$ & $245.67 \pm 45.46^{\mathrm{c}}$ & $292.1 \pm 34.91^{\mathrm{d}}$ & $231.63 \pm 26.94^{\mathrm{c}}$ \\
BW changes (g) & $102 \pm 9.77^{\mathrm{a}}$ & $30.25 \pm 12.29^{\mathrm{b}}$ & $75.33 \pm 14.83^{\mathrm{c}}$ & $120.75 \pm 17.87^{\mathrm{d}}$ & $61.5 \pm 9.57^{\mathrm{e}}$ \\
\hline \multicolumn{7}{c}{ BW: body weight. }
\end{tabular}

\subsection{Measurement of $\mathrm{Hb}, \mathrm{Hct}$, and Serum Iron}

The change in $\mathrm{Hb}$, Hct, and serum iron content of different groups was shown in Table 2. For $\mathrm{Hb}$ content, no significant difference was found between the control group and the Fe-deficient group. The level of $\mathrm{Hb}$ of SFE-Fe group was significantly higher than the ferrous sulfate group, and the $\mathrm{Hb}$ content of ferrous sulfate group was also higher than that of the ferric citrate group. Hct was used to reflect blood viscidity, the level of which was very low after the Fe-deficient period, which was consistent with blood thinning [28]. The Hct level of the Fe-deficient group showed significant reduction after the Fe-depletion period, while the Hct level of groups with the addition of exogenous iron increased sharply. No difference of Hct content was found between SFE-Fe and ferrous sulfate. The result suggested that, when enough external iron was supplemented, ill status caused by low red blood cell volume could receive priority relief. Serum iron refers to iron bound to transferrin, the low level of which could indicate successful modeling. After Fe-repletion, the serum iron content of every group increased with different degrees, especially in the SFE-Fe group, and the ferrous sulfate group.

Table 2. The blood indexes of rats at the end of iron repletion period. Values are expressed as means \pm standard deviations $(n=8)$. Different lowercase letters in the same column indicate significant between groups and intragroup differences, respectively; $(p<0.05)$.

\begin{tabular}{cccccc}
\hline \multirow{2}{*}{ Group } & Iron Repletion & & & \\
\cline { 2 - 6 } & Control & Fe-Deficient & FeSO $_{4}$ & SFC-Fe & Ferric Citrate \\
\hline Initial Hb $(\mathrm{g} / \mathrm{L})$ & $162.25 \pm 20.50^{\mathrm{a}}$ & $74.5 \pm 13.48^{\mathrm{b}}$ & $73.11 \pm 14.24^{\mathrm{b}}$ & $72.75 \pm 12.73^{\mathrm{b}}$ & $71.75 \pm 15.95^{\mathrm{b}}$ \\
Final Hb $(\mathrm{g} / \mathrm{L})$ & $166.25 \pm 22.55^{\mathrm{a}}$ & $71.5 \pm 20.97^{\mathrm{b}}$ & $132.44 \pm 16.99^{\mathrm{c}}$ & $145.75 \pm 16.51^{\mathrm{c}}$ & $113 \pm 21.82^{\mathrm{d}}$ \\
Hb change $(\mathrm{g} / \mathrm{L})$ & $4 \pm 3.74^{\mathrm{a}}$ & $-3 \pm 9.14^{\mathrm{a}}$ & $59.33 \pm 5.27^{\mathrm{b}}$ & $73 \pm 5.89^{\mathrm{c}}$ & $41.25 \pm 7.14^{\mathrm{d}}$ \\
Initial Hct $(\%)$ & $45.65 \pm 4.09^{\mathrm{a}}$ & $15.9 \pm 4.43^{\mathrm{b}}$ & $14 \pm 3.32^{\mathrm{b}}$ & $14.48 \pm 3.55^{\mathrm{b}}$ & $15.35 \pm 5.22^{\mathrm{b}}$ \\
Final Hct $(\%)$ & $48.13 \pm 6.88^{\mathrm{a}}$ & $10.5 \pm 5.55^{\mathrm{b}}$ & $36.78 \pm 4.27^{\mathrm{c}}$ & $39.25 \pm 9.56^{\mathrm{c}}$ & $28.15 \pm 9.61^{\mathrm{d}}$ \\
Initial serum iron $(\mu \mathrm{g} / \mathrm{g})$ & $35.46 \pm 5.14^{\mathrm{a}}$ & $10.37 \pm 2.21^{\mathrm{b}}$ & $10.47 \pm 3.57^{\mathrm{b}}$ & $10.6 \pm 2.74^{\mathrm{b}}$ & $10.6 \pm 1.99^{\mathrm{b}}$ \\
Final serum iron $(\mu \mathrm{g} / \mathrm{g})$ & $35.57 \pm 7.62^{\mathrm{a}}$ & $8.72 \pm 3.32^{\mathrm{b}}$ & $28.59 \pm 10.76^{\mathrm{c}}$ & $31.69 \pm 8.85^{\mathrm{c}}$ & $22.26 \pm 6.11^{\mathrm{d}}$ \\
\hline
\end{tabular}

$\mathrm{Hb}$ : hemoglobin; Hct: hematocrit. 


\subsection{Relative Bioavailability of SCE-Fe}

Iron mainly exists in hemoglobin (65\%), macrophages, and liver in mammals [29]. As shown in Figure $4 \mathrm{a}$, though exogenous iron was added to supplement iron after Fe-depletion, liver iron content of the Fe-deficient group was significantly lower than that of the control group. There was no significant difference between the exogenous iron groups, and it also showed no significant difference with the negative group.
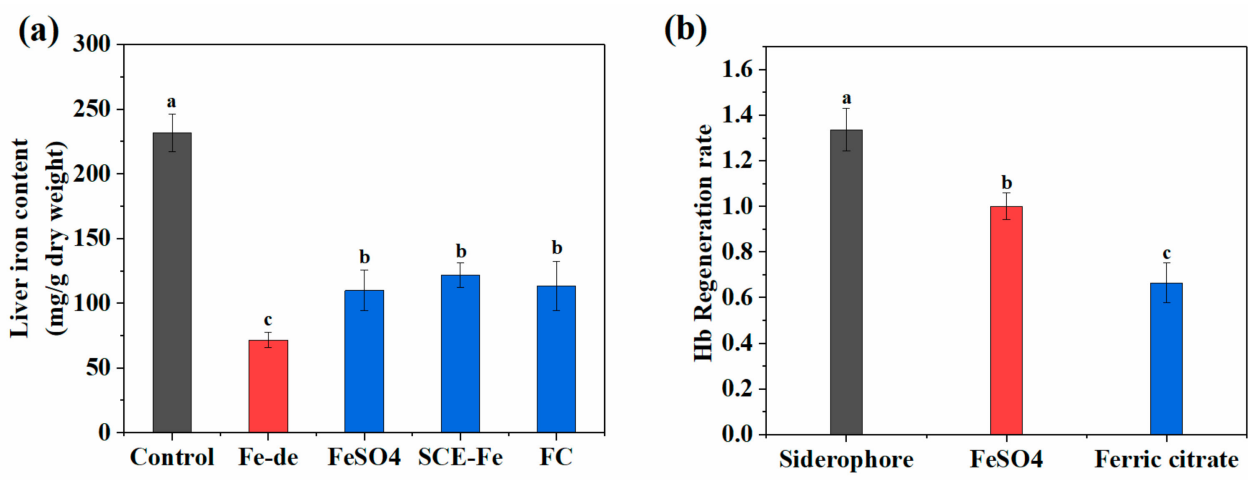

Figure 4. (a) Liver iron concentrations of different groups at the end of iron repletion period (FC-de: Fe-deficient, FC: ferric citrate). (b) Relative biological values of iron of different iron supplements. Values are expressed as means \pm standard deviations $(n=8)$. Bars with different letters are significantly different $(p<0.05)$.

The relative bioavailability of various groups is shown in Figure $4 \mathrm{~b}$. A highly significant difference is shown between them. The bioavailability of SCE-Fe increased notably compared with ferric citrate alone, which was also higher than the value obtained with ferrous sulfate, the positive control. The result suggested that SCF-Fe could promote intestinal absorption of trivalent iron considerably and had strong anemia intervention ability.

\section{Discussion}

As a marine siderophore, SFE is specific for the chelation of iron and binds only to ferric ions [11]. SFE has the structure of $\alpha$-Hydroxy-carboxylate acid ( $\alpha$-hydroxy aspartic acid and citric acid) and amphipathy in the form of polar head and hydrophobic tail [10]. Both contain amphipathy and photochemistry in Fe(III) complexes. Therefore, when algae cells absorb and bind iron, the trivalent iron is reduced to ferrous iron, released due to photodecomposition, and subsequently absorbed via ferrous iron transport [12]. Therefore, as shown in Figure 2a,b, the absorption of SFE-Fe was influenced less by BPDS. Moreover, siderophores, a powerful biological chelating agent, have the potential to be absorbed directly by endocytosis in the intestinal cells, similar to small peptide-chelated iron and ferritin-chelated iron [20]. Chen et al. [7] reported the absorption model of siderophore-chelated iron, which was absorbed by endocytosis when it helped soybeans to resist iron stress.

The photolysis reaction occurring in the unique citric acid-Fe complex of marine siderophores suggested the reducibility of it [12]. Additionally, some siderophore-chelated iron (III) was reduced to ferrous iron by Dcytb reductase and absorbed later through DMT1 on the intestinal epithelial cell surface [19]. We assumed that some trivalent iron chelated by siderophores was reduced to ferrous iron by Dcytd. With ferrous iron released, sodium phytate could combine with it to form a precipitate. As shown in Figure 3a, the absorption of SFE was hardly affected by sodium phytate. This result indicated that siderophores are a powerful biological chelating agent. When combined with trivalent iron, siderophores were primarily absorbed by endocytosis, which could not be depleted by sodium phytate. Therefore, siderophores had a strong ability to resist inhibiting iron absorption.

With external iron added, the serum index level of model groups was improved significantly, and no significant difference was found between the SFE-Fe and ferrous sulfate groups. Therefore, the 
effect of iron supplementation needed to be measured by calculating the relative bioavailability of iron. As shown in Figure 2a the absorption rate of ferrous sulfate was higher than that of SCE-Fe in intestinal cells, while the relative bioavailability was inverted in animal experiments (Figure 4b). It might because that ferrous iron was prone to be oxidized to trivalent iron by oxidizing components from foods during digestion [30], which induced a reduction in bioavailability. On the other hand, ferrous sulfate was prone to be affected by inhibitory components, such as oxalic acid, phytic acid, and polyphenol [31], while SCE-Fe was less affected. The result was consistent with the conclusion that SFE was almost unaffected by sodium phytate in polarized Caco-2 Cell monolayers (Figure 3a). Therefore, the absorption of SCE-Fe was hardly affected by food ingredients.

\section{Methods and Materials}

\subsection{Materials}

Synechococcus sp. PCC7002 was cultivated in the laboratory with Medium, at $30^{\circ} \mathrm{C}$, under a light intensity of $140 \mu \mathrm{mol} \mathrm{m}{ }^{-2} \mathrm{~s}^{-1}$, in $10 \mathrm{~L}$ glass photobioreactors (Figure 5). All Wistar rats were obtained from Shandong Lukang Pharmaceutical Group Co., Ltd. (Shandong, China). Pelletized purified AIN-93G-based diets were obtained from TROPHIC Animal Feed High-Tech Co., Ltd. (Nantong, China). Calcein acetoxymethylester (calcein-AM), cell culture medium (DMEM), and fetal bovine serum were purchased from Gibco (Grand Island, NY, USA). XAD-2 resin, deferoxamine mesylate, sodium phytate, and bathophenanthrolinedisulfonic acid (BPDS) were obtained from Sigma-Aldrich Co. (St. Louis, MO, USA). All other reagents were analytical grade or better.
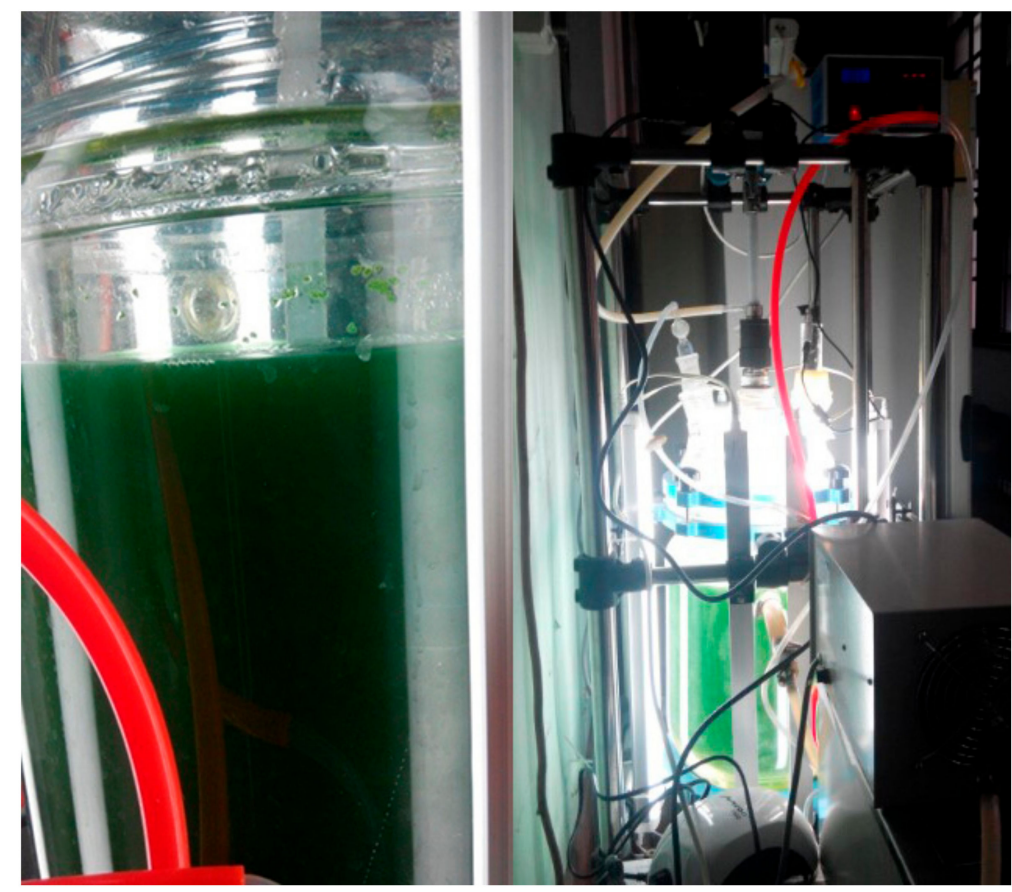

Figure 5. Synechococcus sp. PCC 7002 cultivation in 10 L glass photobioreactors.

\subsection{Preparation of Synechococcus sp. PCC7002 Siderophores}

Synechococcus sp. PCC7002 was harvested and centrifuged at $6000 \times g$ for $15 \mathrm{~min}$, to collect supernatant through a hypervelocity-speed refrigerated centrifuge (GL-21M, Xiangyi, China). After concentration, the supernatant was desalted to obtain siderophore fermentation products (SFP). For obtaining siderophore crude extract (SCE), SFP was purified through the general XARD-2 resin method as follows [32], exhibiting a relatively low purity: The $\mathrm{pH}$ of the SFP was adjusted to 3 in order to release iron from the siderophore. It mixed well with the pretreated XARD-2 resin and was stirred with 
for $6 \mathrm{~h}$. After loading onto the column, it was eluted with Milli-Q water (Millipore, USA) and with 4 column volumes of ultrapure water, and then eluted with 2 to 4 column volumes of $100 \%$ methanol. The obtained liquid sample was rotary-screwed by a rotary evaporator, to remove the methanol, and the mixture was continuously steamed to dryness and then added with water (repeated three times). The final aqueous solution was freeze-dried to obtain a powdery sample. The purity is relatively low, called siderophore crude extraction (hereinafter referred to as SCE). After XARD-2 resin loading onto the column, the SFP with $\mathrm{pH} 3$ was eluted at a flow rate of $<0.1 \mathrm{~L} / \mathrm{min}$, and then it was eluted with 4 column volumes of ultrapure water, $50 \%$ methanol, and $100 \%$ methanol, respectively. Finally, the sample was washed and concentrated according to the above methods. The final power had a higher purity (SFE). The siderophore extracts were arranged in the following order of purity: SFE > SCE > SFP. The samples (obtained by the three ways) of chelated iron all belong to SCI. The siderophore extracts obtained in three different ways are abbreviated in this study.

Siderophores-chelated iron and other samples: $\mathrm{FeSO}_{4}(20 \mathrm{uM})$; the SFE, SCE, and SFP were dissolved in distilled water, adding the same volume of $\mathrm{FeCl}_{3} \bullet 6 \mathrm{H}_{2} \mathrm{O}$. After $6 \mathrm{~h}$ of reaction at $\mathrm{pH}=6.0$ \pm 0.5 , we obtained SFE-Fe, SCE-Fe, and SFP-Fe, and the concentration of $\mathrm{FeCl}_{3} \bullet 6 \mathrm{H}_{2} \mathrm{O}$ was $40 \mathrm{uM}$ $(\mathrm{ICC}=41.88+1.70 \mathrm{uM})$. Before the samples were added into Caco-2 cells, the samples were diluted with 2 times Tyrode solution $(137 \mathrm{mM}$ of $\mathrm{NaCl}, 2.7 \mathrm{mM}$ of $\mathrm{KCl}, 1 \mathrm{mM}$ of $\mathrm{MgCl} 2,1.8 \mathrm{mM}$ of CaCl2, and $5.5 \mathrm{mM}$ of D-glucose). The same method was used for the chelate solution of iron with EDTA, DFB, and sodium phytate, respectively.

\subsection{Construction of the Polarized Caco-2 Cell Monolayers}

Caco-2 cell, obtained from Cell Bank of the Chinese Academy of Sciences (Shanghai, China), was used as a cellular model to study human intestinal absorption. The differentiated cells were obtained according to the method of WU et al. [8], known as the in vitro intestinal model.

Caco- 2 cells were seeded at a density of $5 \times 104$ cells $/ \mathrm{cm}^{2}$, in collagen-treated 24-well plates. The cells were cultured in medium containing high-glucose Dulbecco's modified Eagle medium with $10 \%$ fetal bovine serum, $2 \mathrm{mM}$ of L-glutamine, and $1 \%$ penicillin-streptomycin, at $37^{\circ} \mathrm{C}$, in a $\mathrm{CO}_{2}$ incubator (Heraeus, Germany). The medium was renewed every 2 days. After growth of cell fusion (about 2-3 days), the cells were allowed to differentiate in completed DMES medium for 12 days, to differentiate completely.

The cells were incubated in iron-starvation medium for $24 \mathrm{~h}$, with $4 \mathrm{mg} / \mathrm{L}$ of hydrocortisone, 5 $\mathrm{mg} / \mathrm{L}$ of insulin, $5 \mu \mathrm{g} / \mathrm{L}$ of selenium, $34 \mu \mathrm{g} / \mathrm{L}$ of triiodothyronine, and $20 \mu \mathrm{g} / \mathrm{L}$ of epidermal growth factor for the following experiments.

\subsection{Intestinal Iron Absorption in the Polarized Caco-2 Cell Monolayers}

After absorption by intestinal epithelia, exogenous iron was transformed into a part of the labile iron pool (LIP), rather than being stored in the form of transferrin directly or being synthesized iron-containing enzymes [33]. Therefore, cell iron absorption could be reflected by the iron content of LIP, which negatively correlated with the fluorescence intensity of calcein [34]. Therefore, the absorption of iron content was measured with a calcein kit.

The SFE-Fe was added to culture medium of polarized Caco-2 cell monolayers under different $\mathrm{pH}$ conditions $(\mathrm{pH}=5.5$ and $\mathrm{pH}=7.0)$, to obtain the optimum $\mathrm{pH}$ [35]. The absorption mechanism of siderophore was studied by adding BPDS under optimum $\mathrm{pH}[8,36]$.

\subsection{Animal Experiments}

All animal handling was conducted according to the principles and guidelines outlined in the National Institutes of Health (NIH) Guide for the Care and Use of Laboratory Animals and approved by the Ethical Committee of Animal Care and Use at Ocean University of China (Permit 20001013).

Thirty-two male Wistar male and their lactating mothers were fed Fe-deficient diets at 16 days of age, and young rats were fed normal diets simultaneously. Another 8 pups and their lactating mothers 
were fed normally. When the pups were 22 days old, they were all weaned and separated from the female rats. Thirty-two rats fed Fe-deficient diets continued with the same treatment, and the other eight normal pups continued to be fed a normal diet for 32 days. The $\mathrm{Hb}$ concentration of rats was measured after 32 days for the Fe-deficient group by tail-vein bleeding [2,8].

The Fe-deficient Wistar rats were randomly assigned into $\mathrm{FeSO}_{4}, \mathrm{SFE}-\mathrm{Fe}$, ferric citrate, and Fe-deficient groups. Another eight normal pus were still given a free diet as normal groups. Rats from various groups received the corresponding treatment for 16 days, while Fe-deficient groups were treated with a Fe-deficient diet (Figure 6). After Fe-repletion, the $\mathrm{Hb}$ concentration of rats were measured by tail-vein bleeding after fasting for $16 \mathrm{~h}$. The rats were anesthetized, and blood was drawn from their abdominal aortas. The livers of the rats were removed, frozen with liquid nitrogen, and stored at $-80^{\circ} \mathrm{C}$.

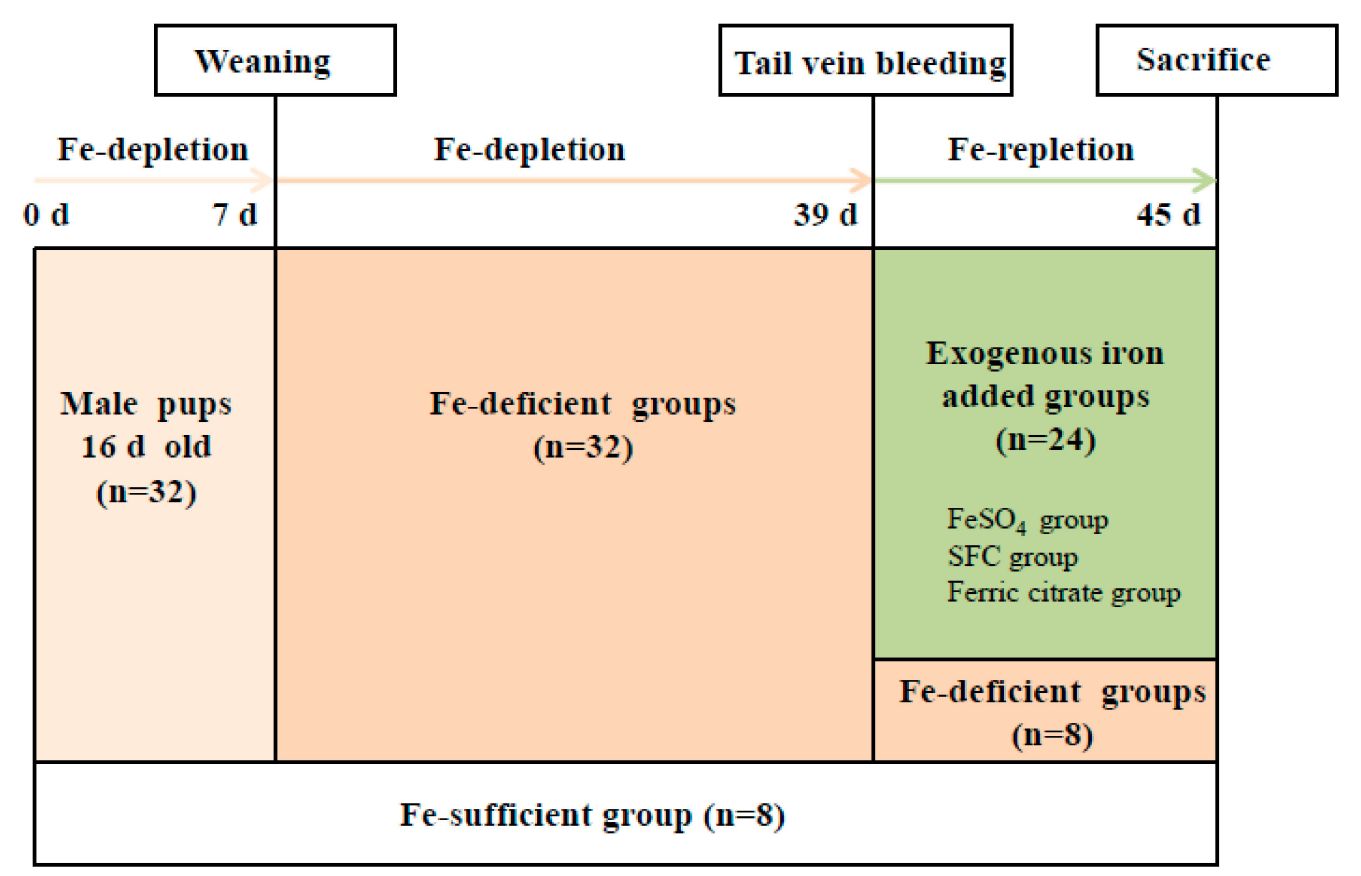

Figure 6. Schematic representation of the plan of animal experiment (the variable $\mathrm{n}$ represents the animal number).

\section{6. $\mathrm{Hb}, \mathrm{Hct}$, and Serum Iron Measurements}

$\mathrm{Hb}$ and Hct were measured through an automated hematology analyzer (Affiliated Hospital of Qingdao University, Qingdao, China). The content of serum iron was measured using a serum iron assay kit (Nanjingjiancheng, Wuhan, China) through an Enzyme mark instrument (Synergy H4, Bio-Tek, USA).

\subsection{Relative Bioavailability of SCE-FE}

After drying to constant weight in the oven, at $90{ }^{\circ} \mathrm{C}$, the liver was weighed and digested to measure iron content by using UV-2550 visible spectrophotometry (SHIMADZU, Japan).

The relative bioavailability of SCE-FE was measured according to the method of Hilty [37].

The $\mathrm{Hb}$ iron pool (mg), assuming a total rat blood volume of $6.7 \%$ body weight (BW) and an iron content in $\mathrm{Hb}$ of $0.335 \%$, was calculated as follows:

$\mathrm{Hb}$ iron pool $(\mathrm{mg})=\mathrm{BW}(\mathrm{kg}) \times 0.067 \times \mathrm{Hb}$ concentration $(\mathrm{g} / \mathrm{L}) \times 3.35$.

$\mathrm{Hb}$ regeneration efficiency $(\%)=[$ final $\mathrm{Hb}$ iron pool $(\mathrm{mg})$ - initial $\mathrm{Hb}$ iron pool $(\mathrm{mg})] /$ total iron consumed $(\mathrm{mg}) \times 100$.

The relative biological value was calculated from the $\mathrm{Hb}$ regeneration efficiencies: 
The relative biological value $(\%)=\mathrm{Hb}$ regeneration efficiency of each animal/Hb regeneration efficiency of the $\mathrm{FeSO}_{4}$ group $\times 100$.

\subsection{Statistical Analysis}

The experimental data were based on triplicate analysis. The statistical analysis was performed by using SPSS 24.0 software. Data were expressed as the mean \pm standard deviation. Mean values were obtained by statistical analysis of variance (one-way ANOVA). Significant differences in treatment means were identified at the level of $p<0.05$.

\section{Conclusions}

This study revealed that SCI was absorbed in the intestine and not affected by sodium phytate, which indicated its good anti-interference ability to food ingredients during iron absorption. SCI exhibited a significant improvement in iron-deficiency anemia, and the bioavailability is higher than that of ferrous sulfate and ferric citrate. Therefore, siderophores derived from Synechococcus sp. PCC7002 could be considered a promising and feasible iron nutritive fortifier supplementation.

Author Contributions: Conceptualization, M.Z.; methodology, R.W.; validation, S.J.; investigation, F.Z.; writing — original draft preparation, X.F.; writing—review and editing, M.Z. and Y.Z.; funding acquisition, M.Z.

Funding: This work was supported by the National Key R\&D Program of China [2018YFD0901005]; Shandong Provincial Key R\&D Program [2018GHY115012]; Natural Science Foundation of Shandong Province [ZR2019MC014].

Conflicts of Interest: The authors declare no conflict of interest.

\section{References}

1. Lv, C.Y.; Zhao, G.H.; Lonnerdal, B. Bioavailability of iron from plant and animal ferritins. J. Nutr. Biochem. 2015, 26, 532-540. [CrossRef] [PubMed]

2. Camaschella, C. Iron deficiency. Blood 2019, 133, 30-39. [CrossRef] [PubMed]

3. Bresgen, N.; Eckl, P.M. Oxidative stress and the homeodynamics of iron metabolism. Biomolecules 2015, 5, 808-847. [CrossRef] [PubMed]

4. McClung, J.P.; Murray-Kolb, L.E. Iron Nutrition and Premenopausal Women: Effects of Poor Iron Status on Physical and Neuropsychological Performance. In Annual Review of Nutrition; Cousins, R.J., Ed.; Annual Reviews: Palo Alto, CA, USA, 2013; Volume 33, pp. 271-288.

5. Kassebaum, N.J.; Jasrasaria, R.; Naghavi, M.; Wulf, S.K.; Johns, N.; Lozano, R.; Regan, M.; Weatherall, D.; Chou, D.P.; Eisele, T.P.; et al. A systematic analysis of global anemia burden from 1990 to 2010. Blood 2014, 123, 615-624. [CrossRef]

6. Reddy, M.B.; Armah, S.M.; Stewart, J.W.; O’Brien, K.O. Iron Absorption from Iron-Enriched Aspergillus oryzae Is Similar to Ferrous Sulfate in Healthy Female Subjects. Curr. Dev. Nutr. 2018, 2, nzy004. [CrossRef]

7. Chen, L.; Dick, W.A.; Streeter, J.G. Production of aerobactin by microorganisms from a compost enrichment culture and soybean utilization. J. Plant Nutr. 2000, 23, 2047-2060. [CrossRef]

8. Wu, H.H.; Zhu, S.Q.; Zeng, M.Y.; Liu, Z.Y.; Dong, S.Y.; Zhao, Y.H.; Huang, H.; Lo, Y.M. Enhancement of Non-heme Iron Absorption by Anchovy (Engraulis japonicus) Muscle Protein Hydrolysate Involves a Nanoparticle-Mediated Mechanism. J. Agric. Food Chem. 2014, 62, 8632-8639. [CrossRef]

9. Zhao, G.H. Phytoferritin and its implications for human health and nutrition. Biochim. Biophys. Acta-Gen. Subj. 2010, 1800, 815-823. [CrossRef]

10. Butler, A.; Theisen, R.M. Iron (III)-siderophore coordination chemistry: Reactivity of marine siderophores. Coord. Chem. Rev. 2010, 254, 288-296. [CrossRef]

11. Neilands, J.B. Microbial iron compounds. Annu. Rev. Biochem. 1981, 50, 715-731. [CrossRef]

12. Homann, V.V.; Edwards, K.J.; Webb, E.A.; Butler, A. Siderophores of Marinobacter aquaeolei: Petrobactin and its sulfonated derivatives. Biometals 2009, 22, 565-571. [CrossRef] [PubMed]

13. Sandy, M.; Butler, A. Microbial Iron Acquisition: Marine and Terrestrial Siderophores. Chem. Rev. 2009, 109, 4580-4595. [CrossRef] [PubMed] 
14. Ito, Y.; Butler, A. Structure of synechobactins, new siderophores of the marine cyanobacterium Synechococcus sp. PCC 7002. Limnol. Oceanogr. 2005, 50, 1918-1923. [CrossRef]

15. Martinez, J.S.; Carter-Franklin, J.N.; Mann, E.L.; Martin, J.D.; Haygood, M.G.; Butler, A. Structure and membrane affinity of a suite of amphiphilic siderophores produced by a marine bacterium. Proc. Natl. Acad. Sci. USA 2003, 100, 3754-3759. [CrossRef]

16. Theurl, I.; Aigner, E.; Theurl, M.; Nairz, M.; Seifert, M.; Schroll, A.; Sonnweber, T.; Eberwein, L.; Witcher, D.R.; Murphy, A.T.; et al. Regulation of iron homeostasis in anemia of chronic disease and iron deficiency anemia: Diagnostic and therapeutic implications. Blood 2009, 113, 5277-5286.

17. Hurrell, R.; Egli, I. Iron bioavailability and dietary reference values. Am. J. Clin. Nutr. 2010, 91, 1461S-1467S. [CrossRef]

18. Dressman, J.B.; Berardi, R.R.; Dermentzoglou, L.C.; Russell, T.L.; Schmaltz, S.; Barnett, J.L.; Jarvenpaa, K.M. Upper Gastrointestinal (GI) pH in Young, Healthy Men and Women. Pharm. Res. 1990, 7, 756-761. [CrossRef]

19. Fuqua, B.K.; Vulpe, C.D.; Anderson, G.J. Intestinal iron absorption. J. Trace Elem. Med. Biol. 2012, 26, 115-119. [CrossRef]

20. Wu, L.; Zou, Y.; Miao, Y.; Zhang, J.; Zhu, S.; Zeng, M.; Wu, H. Dietary gelatin enhances non-heme iron absorption possibly via regulation of systemic iron homeostasis in rats. J. Funct. Foods 2019, 59, 272-280. [CrossRef]

21. Scheers, N.; Sandberg, A. Ascorbic acid uptake affects ferritin, Dcytb and Nramp2 expression in Caco-2 cells. Eur. J. Nutr. 2008, 47, 401-408. [CrossRef]

22. Sharp, P.A. Intestinal Iron Absorption: Regulation by Dietary a Systemic Factors. Int. J. Vitam. Nutr. Res. 2010, 80, 231-242. [CrossRef] [PubMed]

23. Cook, J.D. Diagnosis and management of iron-deficiency anaemia. Best Pract. Res. Clin. Haematol. 2005, 18, 319-332. [CrossRef] [PubMed]

24. Hurrell, R.F. Fortification: Overcoming technical and practical barriers. J. Nutr. 2002, 132, 806S-812S. [CrossRef] [PubMed]

25. Prentice, A.M.; Mendoza, Y.A.; Pereira, D.; Cerami, C.; Wegmuller, R.; Constable, A.; Spieldenner, J. Dietary strategies for improving iron status: Balancing safety and efficacy. Nutr. Rev. 2017, 75, 49-60. [CrossRef] [PubMed]

26. Young, M.F.; Griffin, I.; Pressman, E.; McIntyre, A.W.; Cooper, E.; McNanley, T.; Harris, Z.L.; Westerman, M.; O'Brien, K.O. Utilization of Iron from an Animal-Based Iron Source Is Greater Than That of Ferrous Sulfate in Pregnant and Nonpregnant Women. J. Nutr. 2010, 140, 2162-2166. [CrossRef]

27. Martinez-Torres, C.; Cubeddu, L.; Dillmann, E.; Brengelmann, G.L.; Leets, I.; Layrisse, M.; Johnson, D.G.; Finch, C. Effect of exposure to low temperature on normal and iron-deficient subjects. Am. J. Phys. 1984, 246, R380-R383. [CrossRef]

28. Soares, M.P.; Weiss, G. The Iron age of host-microbe interactions. EMBO Rep. 2015, 16, 1482-1500. [CrossRef]

29. Hoffbrand, V.; Moss, P.A.H. Hoffbrand's Essential Haematology; John Wiley \& Sons Inc.: New York, NY, USA, 2015.

30. Moety, G.A.F.A.; Ali, A.S.; Fouad, R.; Ramadan, W.; Belal, D.S.; Haggag, H. Amino acid chelated iron versus an iron salt in the treatment of iron deficiency anemia with pregnancy: A randomized controlled study. Eur. J. Obstet. Gynecol. Reprod. Biol. 2017, 210, 242-246. [CrossRef]

31. Lei, X.G.; Weaver, J.D.; Mullaney, E.J.; Ullah, A.H.J.; Azain, M.J. Phytase, a New Life for an “Old” Enzyme. Annu. Rev. Anim. Biosci. 2013, 1, 283-309. [CrossRef]

32. Trick, C.G.; Wilhelm, S.W. Physiological-Changes in the Coastal Marine Cyanobacterium Synechococcus sp PCC 7002 Exposed to Low Ferric Ion Levels. Mar. Chem. 1995, 50, 207-217. [CrossRef]

33. Martin, C.D.S.; Garri, C.; Pizarro, F.; Walter, T.; Theil, E.C.; Nunez, M.T. Caco-2 intestinal epithelial cells absorb soybean ferritin by $\mathrm{mu}(2)$ (AP2)-dependent endocytosis. J. Nutr. 2008, 138, 659-666. [CrossRef] [PubMed]

34. Cabantchik, Z.I.; Glickstein, H.; Milgram, P.; Breuer, W. A fluorescence assay for assessing chelation of intracellular iron in a membrane model system and in mammalian cells. Anal. Biochem. 1996, 233, 221-227. [CrossRef] [PubMed]

35. Pantopoulos, K.; Porwal, S.K.; Tartakoe, A.; Devireddy, L. Mechanisms of Mammalian Iron Homeostasis. Biochemistry 2012, 51, 5705-5724. [CrossRef] [PubMed] 
36. Kalgaonkar, S.; Lonnerdal, B. Receptor-mediated uptake of ferritin-bound iron by human intestinal Caco-2 cells. J. Nutr. Biochem. 2009, 20, 304-311. [CrossRef] [PubMed]

37. Hilty, F.M.; Arnold, M.; Hilbe, M.; Teleki, A.; Knijnenburg, J.T.N.; Ehrensperger, F.; Hurrell, R.F.; Pratsinis, S.E.; Langhans, W.; Zimmermann, M.B. Iron from nanocompounds containing iron and zinc is highly bioavailable in rats without tissue accumulation. Nat. Nanotechnol. 2010, 5, 374-380. [CrossRef] 